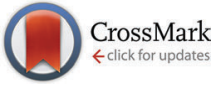

Cite this: Chem. Commun., 2017, 53,732

Received 13th November 2016 Accepted 12th December 2016

DOI: $10.1039 / \mathrm{c} 6 \mathrm{cc0} 09067 \mathrm{~b}$

www.rsc.org/chemcomm

\section{Copper(I)-catalysed transfer hydrogenations with ammonia borane $\uparrow$}

\author{
Eva Korytiaková, Niklas O. Thiel, Felix Pape and Johannes F. Teichert*
}

\begin{abstract}
Highly Z-selective alkyne transfer semihydrogenations and conjugate transfer hydrogenations of enoates can be effected by employing a readily available and air-stable copper(I)/N-heterocyclic carbene (NHC) complex, [IPrCuOH]. As an easy to handle and potentially recyclable $\mathrm{H}_{2}$ source, ammonia borane $\left(\mathrm{H}_{3} \mathrm{NBH}_{3}\right)$ is used.
\end{abstract}

Ammonia borane $\left(\mathrm{H}_{3} \mathrm{NBH}_{3}\right)$, an easy to prepare and manipulate solid, has attracted interest as a potential dihydrogen $\left(\mathrm{H}_{2}\right)$ storage material. ${ }^{1-6}$ Based on the fact that ammonia borane dehydrogenation products (e.g., borazines and polyiminoboranes) can potentially be recycled, ${ }^{7}$ and its exceptionally high $\mathrm{H}_{2}$ content, many studies have been directed toward controlled catalytic release of $\mathrm{H}_{2}$ (dehydrocoupling) from ammonia borane. ${ }^{1-6,8}$ Notably, to a much lesser extent has $\mathrm{H}_{3} \mathrm{NBH}_{3}$ been employed as a reagent for synthesis, for example in the reduction of functional groups or transfer hydrogenations. ${ }^{9-11}$

Copper(I) hydride complexes have emerged as powerful catalysts for a wide variety of reductive transformations, generally relying on silanes $^{12-15}$ or, to a much lesser extent, on tin hydrides ${ }^{16}$ or dihydrogen $^{17,18}$ (Scheme 1). These terminal reducing agents differ conceptually: Si- and Sn-based compounds will deliver a hydride equivalent and the reaction products remain silylated or stannylated until hydrolysis or protonation. On the other hand, reactions with $\mathrm{H}_{2}$ can directly deliver the hydride and proton equivalent, circumventing the need for an additional proton source and reducing the waste generated in these processes. As an example, copper(I)-catalysed alkyne semihydrogenations have recently demonstrated the potential replacement of silanes with $\mathrm{H}_{2} \cdot{ }^{18-20}$ However, most of these procedures require elevated $\mathrm{H}_{2}$ pressure and/or have a limited substrate scope.

On the other hand, homogeneous transfer hydrogenations with copper catalysts are scarce, ${ }^{21,22}$ but circumvent the need

Institut für Chemie, Technische Universität Berlin, Strasse des 17. Juni 115, 10623 Berlin, Germany. E-mail: johannes.teichert@chem.tu-berlin.de;

Fax: +49 30314 28829; Tel: +493031422791

$\dagger$ Electronic supplementary information (ESI) available: Preparation and characterisation data as well as ${ }^{1} \mathrm{H}$ and ${ }^{13} \mathrm{C}$ NMR spectra of all compounds. See DOI: 10.1039/c6cc09067b

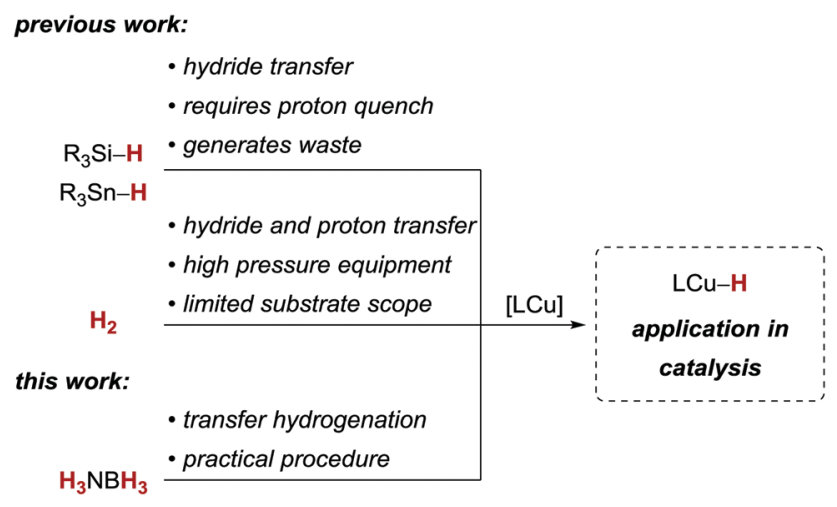

Scheme 1 Hydride and dihydrogen sources employed for copper(।) hydride catalysis.

for high pressure equipment. Given the synthetic utility of copper hydride complexes, we decided to investigate ammonia borane as a reagent for copper-catalysed transfer hydrogenations.

We decided to optimise the copper(I)-catalysed transfer hydrogenation with $\mathrm{H}_{3} \mathrm{NBH}_{3}$ employing alkyne transfer semihydrogenation of pentynol-derived alkyne $\mathbf{1}$ as a test reaction (Table 1). ${ }^{23}$ Due to the reported reactivity with $\mathrm{H}_{2},{ }^{18-20}$ we chose well-defined copper(I)/NHC complexes bearing a copper-oxygen bond as the starting point for our studies. With a copper(I) tertbutanolate complex, generated in situ from [IMesCuCl] and $\mathrm{NaO} t \mathrm{Bu}$, we observed no turnover to the corresponding alkene $Z$-2 at room temperature, but full conversion at $50{ }^{\circ} \mathrm{C}$ (Table 1 , entries 1 and 2). A similar trend was observed with a copper(I) hydroxide/NHC complex, [IPrCuOH] ${ }^{18 b, 24,25}$ which also underwent full conversion to $Z-2$ at $50{ }^{\circ} \mathrm{C}$ (Table 1 , entries 3-5). Increasing the temperature further to $60{ }^{\circ} \mathrm{C}$ led to diminished conversion of $60 \%$ (Table 1 , entry 6 ). The use of [IPrCuOH] is particularly attractive, as it does not require the generally common in situ preactivation (to give activated copper(I) alkoxide complexes) and is air-stable for months. It should be noted that in all cases excellent $Z$-selectivity and negligible overreduction to the corresponding alkane 3 were maintained. This is synthetically 
Table 1 Optimisation of Cu-catalysed transfer semihydrogenation of alkynes

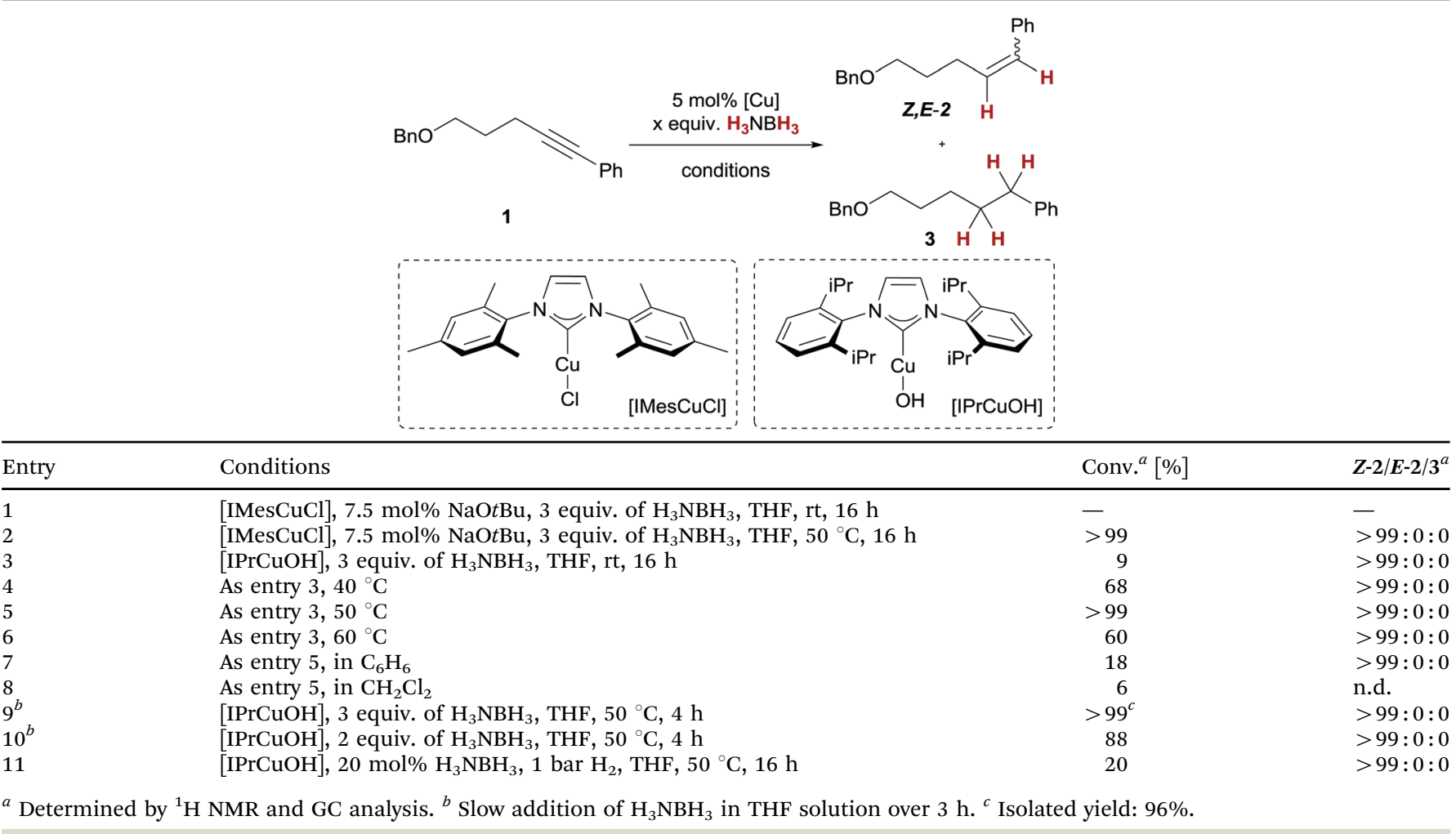

appealing, as alkyne semihydrogenations are commonly carried out with heterogeneous palladium catalysts which generally suffer from these particular limitations. ${ }^{26}$ Furthermore, another report of alkyne transfer semihydrogenation with copper catalysts does not give turnover with internal alkynes, ${ }^{21 c}$ which underscores the orthogonal reactivity of the present catalyst. ${ }^{27}$

The use of THF as a solvent proved to be optimal, as the reactions in benzene and dichloromethane under otherwise similar reaction conditions gave lower conversion of 1 (Table 1, entries 7 and 8). At the onset of the described reactions in THF, gas evolution (most likely $\mathrm{H}_{2}$ ) was observed, accompanied by a relatively slow reaction rate ( $>99 \%$ conversion was reached after $\sim 12 \mathrm{~h}$ reaction time). This hinted at the loss of $\mathrm{H}_{2}$ equivalents for the desired transfer semihydrogenation through concomitant dehydrocoupling. Consequently, when an $\mathrm{H}_{3} \mathrm{NBH}_{3}$ solution in THF was added slowly ( $3 \mathrm{~h}$ ) to the reaction mixture, a generally faster conversion and higher yield of Z-2 were observed (Table 1, entry 9, 96\%). Nevertheless, a total of three equivalents of $\mathrm{H}_{3} \mathrm{NBH}_{3}$ were required for $>99 \%$ conversion since slow addition of two equivalents of ammonia borane did not lead to complete consumption of $\mathbf{1}$ (Table 1 , entry 10). ${ }^{28}$ Based on these results, we decided to probe whether a direct transfer of a hydride equivalent to copper or $\mathrm{H}_{2}$ activation after dehydrocoupling of ammonia borane was present. Therefore, we carried out the alkyne transfer semihydrogenation with a catalytic amount of $\mathrm{H}_{3} \mathrm{NBH}_{3}$ under a $\mathrm{H}_{2}$ atmosphere. These reactions gave only $20 \%$ conversion of 1 (Table 1 , entry 11); hence, we conclude that a direct hydride transfer mechanism is present.

With the optimised reaction conditions in hand, we explored the substrate scope of the copper-catalysed alkyne transfer semihydrogenation. A variety of phenylacetylene derivatives with both electron-donating and electron-withdrawing functional groups 4a-4g could successfully be transformed into alkenes $5 \mathbf{a}-\mathbf{5} \mathbf{g}$ with good yields and consistently high $Z$-selectivity (Table 2, entries 1-7). Of note is the low conversion achieved with 3-anisole derivative 4d (30\%, Table 2, entry 4$)$; we suspect substrate coordination detrimental to the catalyst, which is absent with the other two regioisomers $\mathbf{4 c}$ and $\mathbf{4 e}$ (Table 2, entries 3 and 5). With strongly electron-withdrawing substituents (as in $\mathbf{5 h} \mathbf{h} \mathbf{5} \mathbf{j}$, Table 2, entries 8-10), we observed partial overreduction to the corresponding alkanes, although the $Z / E$-ratios remained high. The same is true for the acetophenone derivative $\mathbf{4 k}$, where overreduction to the benzyl alcohol $\mathbf{5 k}$ was detected (Table 2 , entry 11 ). ${ }^{29} \mathrm{~A}$ variety of $Z$-stilbenes 5l-5o can be synthesised from the corresponding tolane derivatives 4l-4o with good yields (Table 2, entries 12-15). Here, a similarly detrimental influence of the electron-withdrawing trifluoromethyl substituent in $\mathbf{5 0}$ was observed as $8 \%$ alkane was detected (Table 2, entry 15). The alkyne transfer semihydrogenation can also be applied to dialkylalkynes, as demonstrated by the formation of $Z$-alkenes $\mathbf{5 p}$ and $\mathbf{5 q}$ (Table 2, entries 16 and 17). For full consumption of the former, one more equivalent of $\mathrm{H}_{3} \mathrm{NBH}_{3}$ was added. Finally, protected allyl alcohols $\mathbf{5 r}$ and $\mathbf{5 s}$ can be obtained with high $Z$-selectivity from the corresponding propargylic silyl ethers $4 \mathbf{r}$ and $\mathbf{4 s}$ (Table 2, entries 18 and 19). Generally, the obtained yields are good; in some cases we observed undesired hydroboration/ oxidation of the alkene products. ${ }^{23}$ We attribute the somewhat diminished yields to this side reaction.

Finally, we investigated the transfer semihydrogenation of alkyl and aryl propiolates 6 (Scheme 2). In both cases the desired 
Table 2 Cu-catalysed transfer semihydrogenation of alkynes with ammonia borane: substrate scope

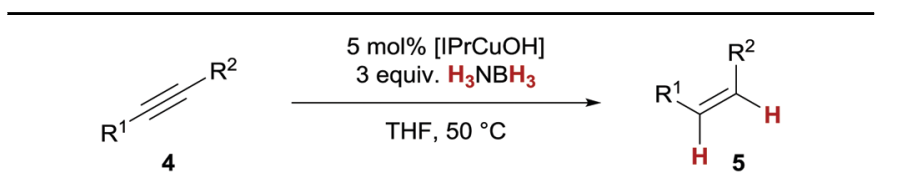

\begin{tabular}{llll}
\hline Entry & Product & Yield [\%] & Z/E/alkane \\
\end{tabular}

5a: $\mathrm{R}=4-\mathrm{Me}$

1<smiles>[R]#CC=Cc1ccccc1</smiles>

5b: $\mathrm{R}=4-\mathrm{Bu}$

5c: $\mathrm{R}=4-\mathrm{OMe}$

5d: $\mathrm{R}=3-\mathrm{OMe}$

5e: $\mathrm{R}=2$-OMe

5f: $\mathrm{R}=\mathrm{Br}$

5g: $\mathrm{R}=\mathrm{Cl}$

5h: $\mathrm{R}=\mathrm{CO}_{2} \mathrm{Me}$

5i: $\mathrm{R}=\mathrm{CN}$

5j: $\mathrm{R}=\mathrm{CF}_{3}$

$5 \mathbf{k}$<smiles>CC(O)c1ccc(/C=C/CCCOCc2ccccc2)cc1</smiles>

5l: $\mathrm{R}=\mathrm{H}$<smiles>[R][R]1ccccc1/C=C\c1ccccc1</smiles>

5m: $\mathrm{R}=4-\mathrm{OMe}$

5n: $\mathrm{R}=4-\mathrm{Cl}$

5o: $\mathrm{R}=4-\mathrm{CF}_{3}$

5p:

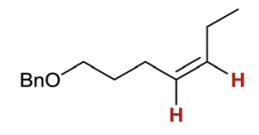

5q:<smiles>CCCCCC=Cc1ccccc1</smiles>

5r:<smiles>CCCC=CCO[PbH2]</smiles>

5s:<smiles>[PH3]OC/C=C\CO[AsH3]</smiles>

80 conv.
$>99: 0: 0$ $>99: 0: 0$

$92: 0: 8$

$>99: 0: 0$

$95: 5: 0$

$>99: 0: 0$

$>99: 0: 0$

$99: 0: 0$

$80: 0: 20$

$89: 4: 7$

$81: 0: 19$

$84: 1: 15$

$99: 0: 0$

(1)

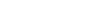

$>99: 0: 0$ (

(a)

$>99: 0: 0$

$7^{a}$

8

9

$10^{c}$

$11^{c}$

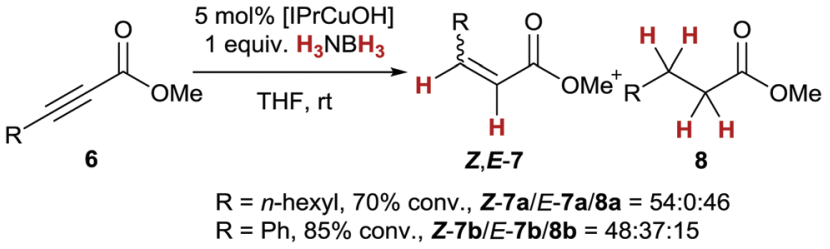

Scheme 2 Transfer semihydrogenation of propiolates.

$Z$-acrylates $7 \mathbf{a}$ and $\mathbf{7 b}$ were found, however, in the presence of overreduced esters $\mathbf{8 a}$ and $\mathbf{8 b}$. This indicated the viability of a conjugate transfer hydrogenation of the initially formed acrylates 7 . We therefore decided to investigate the conjugate transfer hydrogenation of $\alpha, \beta$-unsaturated esters with ammonia borane next.

After initial optimisation we also found that conjugate transfer hydrogenation of enoates 9 with ammonia borane was feasible under similar reaction conditions (Table 3). Conjugate transfer hydrogenation of disubstituted ethyl esters 9a-9i could be realised with generally good isolated yields when the reaction was carried out under previously optimised conditions (Table 3, entries 1-9). Isolated yields for esters 10 generally are higher than in the alkyne transfer semihydrogenation. This is possibly due to the absence of a reactive double bond in the products, which could lead to further reactions. Only thiophene derivative 10f was obtained in a somewhat lower yield (Table 3, entry 6). Of note is the different reactivity of the catalyst toward double bond isomers: while the $E$-enoate 9d underwent smooth conversion to the desired saturated product 10d (Table 3, entry 4), the reaction with $Z$-enoate 9e proceeded sluggishly (46\% conversion to 10e after $16 \mathrm{~h}$ ) under otherwise similar conditions (Table 3, entry 5). Higher substituted acrylates $\mathbf{1 0 j}-\mathbf{1 0 l}$ proved to be more difficult to obtain, most probably due to steric hindrance (Table 3, entries 10-12). However, by addition of 6 equivalents of $\mathrm{H}_{3} \mathrm{NBH}_{3}$, esters $\mathbf{1 0 j - 1 0 l}$ could be isolated in good yields. ${ }^{30}$

Table 3 Cu-catalysed conjugate transfer hydrogenation: substrate scope

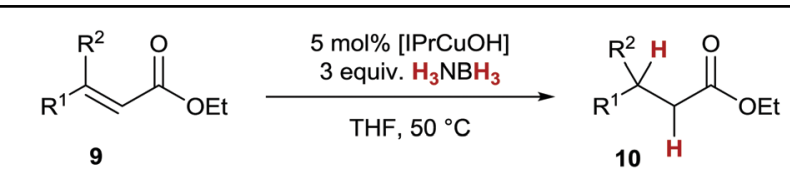

\begin{tabular}{|c|c|c|}
\hline Entry & Product & Yield [\%] \\
\hline $1^{a}$ & 10a: $\mathrm{R}^{1}=\mathrm{Ph}, \mathrm{R}^{2}=\mathrm{H}$ & 82 \\
\hline $2^{a}$ & 10b: $\mathrm{R}^{1}=2$-naphthyl, $\mathrm{R}^{2}=\mathrm{H}$ & 83 \\
\hline $3^{a}$ & 10c: $\mathrm{R}^{1}=4-\mathrm{OMe}-\mathrm{C}_{6} \mathrm{H}_{4}, \mathrm{R}^{2}=\mathrm{H}$ & 83 \\
\hline 4 & 10d: $\mathrm{R}^{1}=4-\mathrm{OBn}-\mathrm{C}_{6} \mathrm{H}_{4}, \mathrm{R}^{2}=\mathrm{H}$ & 87 \\
\hline $5^{b}$ & 10e: $\mathrm{R}^{1}=\mathrm{H}, \mathrm{R}^{2}=4-\mathrm{OBn}-\mathrm{C}_{6} \mathrm{H}_{4}$ & 46 conv. \\
\hline 6 & 10f: $\mathrm{R}^{1}=2$-thiophenyl, $\mathrm{R}^{2}=\mathrm{H}$ & 66 \\
\hline $7^{a}$ & 10g: $\mathrm{R}^{1}=$ cyclohexyl, $\mathrm{R}^{2}=\mathrm{H}$ & 88 \\
\hline 8 & 10h: $\mathrm{R}^{1}=4-\mathrm{Br}^{-} \mathrm{C}_{6} \mathrm{H}_{4}, \mathrm{R}^{2}=\mathrm{H}$ & 82 \\
\hline 9 & 10i: $\mathrm{R}^{1}=4-\mathrm{CF}_{3}-\mathrm{C}_{6} \mathrm{H}_{4}, \mathrm{R}^{2}=\mathrm{H}$ & 89 \\
\hline $10^{c}$ & 10j: $\mathrm{R}^{1}=2$-naphthyl, $\mathrm{R}^{2}=\mathrm{Me}$ & 93 \\
\hline $11^{c}$ & 10k: $\mathrm{R}^{1}=\mathrm{Ph}, \mathrm{R}^{2}=\mathrm{Me}$ & 76 \\
\hline $12^{c}$ & 10l: $\mathrm{R}^{1}=\mathrm{Ph}, \mathrm{R}^{2}=\mathrm{Ph}$ & $73^{d}$ \\
\hline
\end{tabular}

${ }^{a}$ These reactions reached $>99 \%$ conversion with 2 equiv. of $\mathrm{H}_{3} \mathrm{NBH}_{3}$.

${ }^{b}$ The methyl ester of 9 e was employed. ${ }^{c} 6$ equiv. of $\mathrm{H}_{3} \mathrm{NBH}_{3}$ was used.

${ }^{d}$ Contains $14 \%$ of the starting material. 
In summary, we have developed copper(I) hydride-mediated transfer hydrogenation reactions employing ammonia borane $\left(\mathrm{H}_{3} \mathrm{NBH}_{3}\right)$ as a $\mathrm{H}_{2}$ equivalent. Alkynes can be converted into the corresponding alkenes with high $Z$-selectivities in transfer semihydrogenations. Also, the protocol enables a conjugate transfer hydrogenation of enoates. An air-stable and preactivated copper(I) hydroxide/NHC complex is used, circumventing the need for generally common in situ activation of the copper catalyst. We think that these results could be of importance with foresight to the use of readily available transition metal catalysts (such as copper) for transfer hydrogenations.

This research was supported by the Fonds der Chemischen Industrie (Liebig-Stipendium for J. F. T.) and the German Academic Exchange Service (DAAD) through a Leistungsstipendium (for E. K.). F. P. is supported by a predoctoral scholarship of the Berlin International Graduate School of Natural Sciences and Engineering (BIG-NSE). We kindly thank Prof. Dr. Martin Oestreich (TU Berlin) for generous support. Prof. Dr. Gerhard Erker (WWU Münster) is thanked for fruitful discussion.

\section{Notes and references}

1 C. W. Hamilton, R. T. Baker, A. Staubitz and I. Manners, Chem. Soc. Rev., 2009, 38, 279-293.

2 A. Staubitz, A. P. M. Robertson and I. Manners, Chem. Rev., 2010, 110, 4079-4124.

3 H.-L. Jiang and Q. Xu, Catal. Today, 2011, 170, 56-63.

4 F. H. Stephens, V. Pons and R. T. Baker, Dalton Trans., 2007, 2613-2626.

5 P. Wang and X.-D. Kang, Dalton Trans., 2008, 5400-5413.

6 J. Yang, A. Sudik, C. Wolverton and D. J. Siegel, Chem. Soc. Rev., 2010, 39, 656-675.

7 (a) Y. Tan and X. Yu, RSC Adv., 2013, 3, 23879-23894; (b) N. C. Smythe and J. C. Gordon, Eur. J. Inorg. Chem., 2010, 509-521.

8 (a) A. Rossin and M. Peruzzini, Chem. Rev., 2016, 116, 8848-8872;

(b) R. Waterman, Chem. Soc. Rev., 2013, 42, 5629-5641; (c) R. J. Less, R. L. Melen and D. S. Wright, RSC Adv., 2012, 2, 2191-2199; (d) G. Alcaraz and S. Sabo-Etienne, Angew. Chem., Int. Ed., 2010, 49, 7170-7179.

9 X. Yang, Z. Xie, J. He and L. Yu, Chin. J. Org. Chem., 2015, 35, 603-609. 10 For selected examples, see: $(a)$ Z. M. Heiden and T. B. Rauchfuss, J. Am. Chem. Soc., 2007, 129, 14303-14310; (b) N. Blaquiere, S. DialloGarcia, S. I. Gorelsky, D. A. Black and K. Fagnou, J. Am. Chem. Soc., 2008, 130, 14034-14035; (c) Y. Jiang, O. Blacque, T. Fox, C. M. Frech and H. Berke, Organometallics, 2009, 28, 5493-5504; (d) R. BarriosFrancisco and J. J. García, Appl. Catal., A, 2010, 385, 108-113; (e) H. Dong and H. Berke, J. Organomet. Chem., 2011, 696, 1803-1808; $(f)$ T.-P. Lin and J. C. Peters, J. Am. Chem. Soc., 2013, 135, 15310-15313; $(g)$ J. K. Pagano, J. P. W. Stelmach and R. Waterman, Dalton Trans., 2015, 44, 12074-12077.

11 For the use of ammonia borane as the $\mathrm{H}_{2}$ donor in transfer hydrogenations with alkynes and/or alkenes, see for example: (a) R. Barrios-Francisco and J. J. García, Appl. Catal., A, 2010, 385, 108-113; (b) M. E. Sloan, A. Staubitz, K. Lee and I. Manners, Eur. J. Org. Chem., 2011, 672-675; (c) C. E. Hartmann, V. Jurčík, O. Songis and C. S. J. Cazin, Chem. Commun., 2013, 49, 1005-1007; (d) S. Fu,
N.-Y. Chen, X. Liu, Z. Shao, S.-P. Luo and Q. Liu, J. Am. Chem. Soc., 2016, 138, 8588-8594.

12 A. J. Jordan, G. Lalic and J. P. Sadighi, Chem. Rev., 2016, 116, 8318-8372.

13 C. Deutsch, N. Krause and B. H. Lipshutz, Chem. Rev., 2008, 108, 2916-2927.

14 S. Rendler and M. Oestreich, Angew. Chem., Int. Ed., 2007, 46, 498-504.

15 B. H. Lipshutz, in Copper(I)-mediated 1,2- and 1,4-Reductions. Modern Organocopper Chemistry, ed. N. Krause, Wiley-VCH, Weinheim, 2002, pp. 167-187.

16 (a) B. H. Lipshutz, C. Ung and S. Sengupta, Synlett, 1989, 64-66; (b) L. T. Leung, S. K. Leung and P. Chiu, Org. Lett., 2005, 7, 5249-5252.

17 (a) W. S. Mahoney and J. M. Stryker, J. Am. Chem. Soc., 1989, 111, 8818-8823; (b) H. Shimizu, D. Igarashi, W. Kuriyama, Y. Yusa, N. Sayo and T. Saito, Org. Lett., 2007, 9, 1655-1657; (c) K. Junge, B. Wendt, D. Addis, S. Zhou, S. Das, S. Fleischer and M. Beller, Chem. - Eur. J., 2011, 17, 101-105.

18 (a) F. Pape, N. O. Thiel and J. F. Teichert, Chem. - Eur. J., 2015, 21, 15934-15938; (b) N. O. Thiel and J. F. Teichert, Org. Biomol. Chem., 2016, 14, 10660-10666.

19 K. Semba, R. Kameyama and Y. Nakao, Synlett, 2015, 318-322.

20 T. Wakamatsu, K. Nagao, H. Ohmiya and M. Sawamura, Organometallics, 2016, 35, 1354-1357.

21 For examples of homogeneous copper-catalysed transfer hydrogenations, see: (a) J. W. Yang and B. List, Org. Lett., 2006, 8, 5653-5655; (b) K. Saito, Y. Kajiwara and T. Akiyama, Angew. Chem., Int. Ed., 2013, 52, 13284-13288; (c) H. Cao, T. Chen, Y. Zhou, D. Han, S.-F. Yin and L.-B. Han, Adv. Synth. Catal., 2014, 356, 765-769.

22 For alkyne transfer semihydrogenations with ammonia borane and heterogeneous catalysts, see: (a) D. van der Waals, A. Pettman and J. M. J. Williams, RSC Adv., 2014, 4, 51845-51849; (b) E. Vasilikogiannaki, I. Titilas, G. Vassilikogiannakis and M. Stratakis, Chem. Commun., 2015, 51, 2384-2387.

23 See the ESI $\dagger$ for details and additional optimisation (reaction parameters, $\mathrm{Cu}$ catalysts, addition mode) data.

24 G. C. Fortman, A. M. Z. Slawin and S. P. Nolan, Organometallics, 2010, 29, 3966-3972.

25 For the use of IPrCuOH as the catalyst in carboxylation reactions, see: (a) I. I. F. Boogaerts, G. C. Fortman, M. R. L. Furst, C. S. J. Cazin and S. P. Nolan, Angew. Chem., Int. Ed., 2010, 49, 8674-8677; (b) O. Santoro, F. Lazreg, Y. Minenkov, L. Cavallo and C. S. J. Cazin, Dalton Trans., 2015, 44, 18138-18144.

26 (a) C. Oger, L. Balas, T. Durand and J.-M. Galano, Chem. Rev., 2013, 113, 1313-1350; (b) M. Crespo-Quesada, F. Cárdenas-Lizana, A.-L. Dessimoz and L. Kiwi-Minsker, ACS Catal., 2012, 2, 1773-1786; (c) H. Lindlar, Helv. Chim. Acta, 1952, 35, 446-450.

27 The transfer semihydrogenation of terminal alkynes with the present catalyst leads to mixtures of products with the terminal alkene and a dimerised 1,3-diene as the major products. See the ESI $\dagger$ for details.

28 Reaction analysis by ${ }^{11} \mathrm{~B}$ NMR shows the formation of polyaminoboranes (see the ESI $\dagger$ for details), which indicates the transfer of 1 equiv. of $\mathrm{H}_{2}$ per molecule of ammonia borane. This could account for the high loadings of ammonia borane required.

29 The reduction of ketones with $\mathrm{H}_{3} \mathrm{NBH}_{3}$ is most likely an uncatalysed process, see: (a) G. C. Andrews and T. C. Crawford, Tetrahedron Lett., 1980, 21, 693-696; (b) G. C. Andrews, Tetrahedron Lett., 1980, 21, 697-700; (c) L. Shi, Y. Liu, Q. Liu, B. Wei and G. Zhang, Green Chem., 2012, 14, 1372-1375.

30 Even though varying amounts of $\mathrm{H}_{3} \mathrm{NBH}_{3}$ are necessary in these transformations, it should be noted that from a practical perspective, the exact amount required can be determined by in situ analysis of the reaction: later addition of further equivalents of $\mathrm{H}_{3} \mathrm{NBH}_{3}$ is possible, as the catalyst remains active in solution. 